\title{
UNDERSTANDING VOLATILITY TRANSMISSION MECHANISM AMONG THE CDS MARKETS: EUROPE \& NORTH AMERICA VERSUS BRAZIL \& TURKEY
}

\author{
HAKKI ARDA TOKAT *
}

\begin{abstract}
This study examines the volatility transmission mechanism among the developed and emerging CDS markets by employing multivariate GAR$\mathrm{CH}$ modeling. As the globalization resulted with more integration of financial markets, it is important for market participants to know how the shocks and volatility are transmitted over time across the markets. It is also important to know if the volatility transmission changes during the times of financial crises. Significant transmission of shocks and volatility is found among different CDS markets. Contrary to previous studies showing one-way transmission of volatility from developed to emerging markets, interdependence detected among different markets indicates the presence of cross-market hedging.
\end{abstract}

Keywords: Volatility transmission; MV GARCH; CDS markets.

\section{Resumo}

Este estudo examina o mecanismo de transmissão de volatilidade do mercado de CDS entre países emergentes e desenvolvidos, usando GARCH multivariado. Como a globalização resultou em uma maior integração entre os mercados financeiros, é importante para os participantes do mercado saber como os choques e a volatilidade são transmitidos entre mercados ao longo do tempo. Também é importante saber se a transmissão de volatilidade muda durante épocas de crises financeiras. Os resultados mostram significante transmissão de choques e de volatilidade entre diferentes mercados de CDS. Contrariamente a estudos anteriores mostrando transmissão de volatilidade em uma única direção dos países desenvolvidos para os emergentes, a interdependência entre diferentes mercados indica a presença de hedge cruzado entre mercados.

Palavras-chave: Transmissão de volatilidade; MV GARCH; Mercados de CDS.

JEL classification: G15

\footnotetext{
* Department of International Entrepreneurship, PlaceNameplaceTOBB PlaceTypeUniversity of Economics and Technology, Ankara / Turkey. E-mail: hapersonnametokat@etu.edu.tr
} 


\section{Summary}

In the last two decades, increasing integration of financial markets throughout the world has generated interest in knowing how the financial shocks are transmitted across the markets. However, much attention has been focused on examining the volatility transmission mechanism that exists on major financial equity markets. In the wake of recent global credit crisis, the upsurge of interest in studying the interaction between the financial markets is inevitable, particularly in credit derivatives markets where the crisis boomed from. This paper examines the volatility transmission relationship between the CDS markets of developed and emerging markets by employing multivariate GARCH modeling. During the first stages of crisis in credit markets, emerging markets had been seen as the safe havens of global financial world as they have relatively cleaner balance sheets carrying lower volume of structural financial products which are blamed for the cause of this crunch. However, increasing sovereign CDS spreads for those markets may be a sign that the financial investors put them in the same basket with the developed ones in terms of risk level. As the globalization resulted with more integration of financial markets, it is important for market participants to know how the shocks and volatility are transmitted over time across the markets. In this study, the break analysis is conducted to see if the transmission mechanism shows any difference when there is a structural break in the series. Significant transmission of shocks and volatility is found among different CDS markets. Contrary to previous studies showing one-way transmission of volatility from developed to emerging markets, interdependence detected among different markets indicates the presence of cross-market hedging.

\section{Introduction}

Along with the recent financial turmoil, the issue of volatility transmission has gone on the stage once more, a decade after the Asian crisis. In the last two decades, increasing integration of financial markets throughout the world has already generated interest in knowing how the financial shocks are transmitted across the markets. However, much attention has been focused on examining the volatility transmission mechanism that exists on major financial equity markets. Some important papers studying the volatility transmission and its spillover effects on regional markets are those by Hamao \& Masulis (1990), King \& Wadhwani (1990), Lin et al. (1994), Engle (1993), and Karolyi (1995), Tanizaki \& Hamori (2008). Volatility transmission literature has also extended its boundaries by studies examining this mechanism on additional markets such as energy markets by Ewing et al. (2002) commodity futures markets by Xu \& Fung (2005), foreign exchange markets by place City Kearney \& Patton (2000) or sector indexes by Hassan \& Malik (2007) but not on credit derivatives markets.

In the wake of last global credit crisis, the upsurge of interest in studying the interaction between the financial markets is inevitable, particularly in credit derivatives markets where the crisis boomed from. This paper examines the volatility transmission relationship between the CDS markets of developed and emerging markets. During the first stages of crisis in credit markets, emerging markets had been seen as the safe havens of global financial world as they have relatively cleaner balance sheets carrying lower volume of struc- 
tural financial products which are blamed for the cause of this crunch. However, increasing sovereign CDS spreads for those markets may be a sign that the financial investors put them in the same basket with the developed ones in terms of risk level, (see Figure 1).

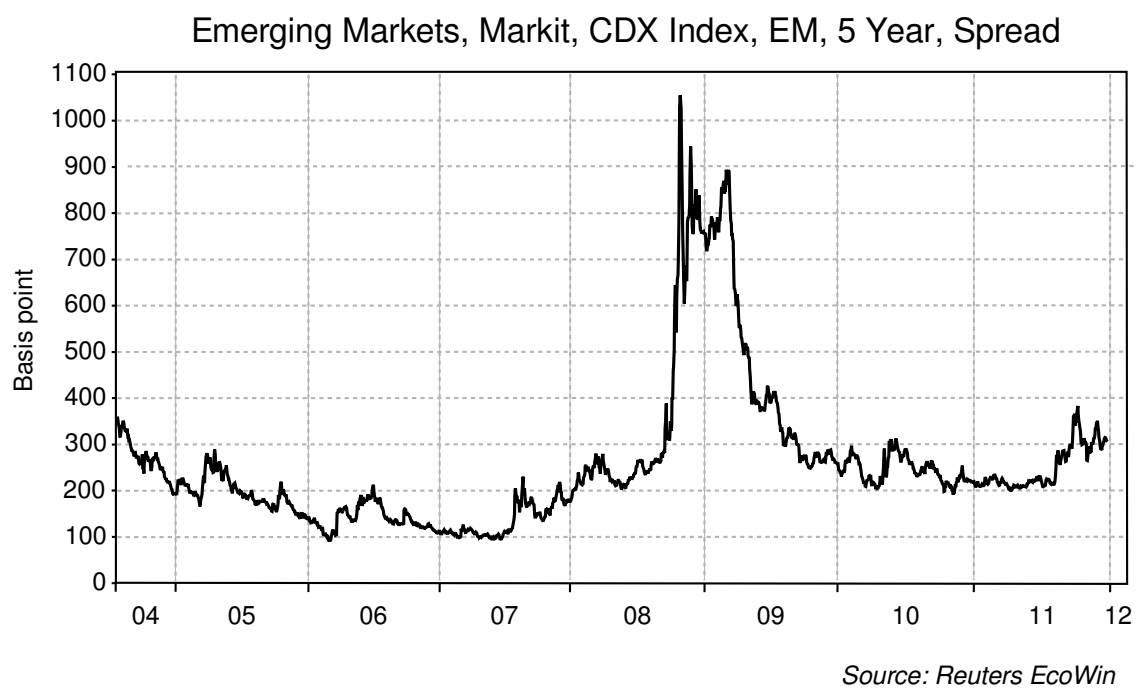

Figura 1: Credit Default Swap Index of sovereign issuers from three regions: Latin America, Eastern Europe, the Middle East and Africa, and Asia

In the past decade, the credit derivatives market has experienced rapid growth, and among credit derivatives, the credit default swap $(C D S)^{1}$ has become the most widely traded instrument for transferring credit risk. According to survey data coordinated by the International Swaps and Derivatives Association (ISDA), by the end of 2007, the total notional amount of outstanding CDS contracts grew to $\$ 62.2$ trillion. CDS contracts can help isolate credit risk from other factors affecting bond prices such as illiquidity premiums, and thus may provide more accurate pricing and cleaner measurement of credit risk than is available from the underlying debt markets.

Considering the CDS market's rapid growth, a limited number of work has been done on CDSs that focus mostly on pricing determinants, performance of pricing models, and the majority has concentrated on corporate CDSs such as Blanco et al. (2005). They investigate the long- and short-term relationships of corporate bonds with their corresponding CDSs and conclude that shortterm deviations from theoretical parity are due to a lead for CDS prices over credit spreads in price discovery. Regarding sovereign issuers, Chan-Lau \& Kim (2004) examine the equilibrium price relationships and price discovery in the CDS, bond and equity markets for eight emerging countries and find that the CDS and bond spreads converge even in the presence of external market pressures. In a recent study, Weigel \& Gemmill (2006) investigate the creditworthiness of country-region Argentina, country-region Brazil, countryregion Mexico, and place country-region Venezuela, and find that the monthly variation in measures of creditworthiness for these four countries is driven mainly by global and regional factors rather than country-specific fundamen-

\footnotetext{
${ }^{1}$ For a better understanding of the nature of CDS contracts, see place City Hull (2008)
} 
tals. Their results highlight the existence of systematic factors that drive fluctuations in the sovereign spreads of emerging markets. In a very recent study, Meng et al. (2009) investigate the volatility transmission mechanism in such a setup where the volatility originates from the CDS market and transmits through the bond and equity markets. Their hypothesis is based on the possible effect of potential insider trading and increased trading activity due to private credit information. However, their results do not support their argument and they find the volatility in any market commonly transmitting to the other two markets.

Early research on volatility transmission has shown the dominance of U.S. based financial markets over the emerging ones (see Arshanapalli \& Doukas 1993, King \& Wadhwani 1990). Moreover, the recent studies point out the growing dependency of emerging markets on the developed financial markets (see Frankel \& Roubini 2001, Dailami et al. 2005, Chukwuogor 2007). In this perspective, the interaction mechanism among the developed and emerging financial markets seems to be overlooked by only focusing on unidirectional dependency from developed to emerging markets.

This time, in contrast to previous research questions on volatility transmission literature, the question raised is whether the volatility is transmitted among the developed and emerging financial markets in both directions with a specific focus on CDS markets. The emerging markets used in the analysis are Brazil and Turkey. These countries are picked based on certain criteria. First, Brazil and Turkey are the two emerging markets which have been evaluated together in the same investment basket by the financial investors. Analysis of these two countries in this paper's context would provide further insight into the portfolio allocation decisions of financial participants. Second, recent changes in Brazilian economy and the upgrading of Brazil to investment grade (triple B minus) by Standard and Poor raises the question whether the market participants are going to separate the baskets for Turkey and Brazil and whether the Brazilian market will have a leading role among the emerging markets. To represent the developed markets, there are corporate CDS indices available for the analysis, namely iTraxx Crossover in Europe and CDX in North America. The iTraxx Crossover (iTraxx XO) index measures the cost of protecting 50 risky European companies' debt (corporate default risk). In other words, this index refers to CDS of high-yield bonds. The index composition is updated twice a year, with the roll dates of each new index being either March 20 or September 20. Each reference entity is equally weighted. In case of a firm's default, the defaulted firm is removed from the index portfolio and the nominal value of the contract declines by $1 / 50$, i.e. $2 \%$. The index has been widely used by financial institutions as a hedging tool for a huge variety of risky assets. The CDX index represents the average CDS premium of the 125 most liquid investment-grade companies, located in North America, distributed among the five sub-sectors.

To see the differences in the dynamics of the volatility transmission in period of crises and low volatile environments, we conducted an ICSS break analysis to catch any structural break in the series. Then, the model is conducted to the sub-series to see if there is any behavioral changes in the period of crisis..

The results of this study indicate that first; there is a volatility transmission mechanism running among the developed and emerging CDS markets. Second, contrary to previous studies showing one-way dependency from de- 
veloped to emerging markets; Brazilian CDS market is found to affect other markets' volatility through its own shocks as well as its past volatility. The results are revealing for building accurate cross-hedging strategies for financial market participants.

The paper is organized as follows: Section 3 describes the methodology and data. In section 4 we provide the empirical results. The last section concludes and discusses some of the hedging implications.

\section{Methodology and Data}

An autoregressive conditional heteroskedasticity (ARCH) specification developed by Engle (1982) and, later, generalized by Bollerslev et al. (1988) has been widely used in modeling the volatility of high-frequency financial timeseries data. Multivariate generalized autoregressive conditional heteroscedasticity (MGARCH) models have been commonly used to estimate the spillover effects in mean and volatility among different markets (see Hassan \& Malik 2007, Frank \& Hesse 2009, Savva 2009, Milunovich \& Thorp 2006). In line with related literature, we follow the same approach and use MGARCH model to identify the volatility transmission relationship between the markets identified in the preceding section. At first, the following the mean equation is estimated for each return series:

$$
\Delta \mathrm{p}_{\mathrm{i}, \mathrm{t}}=\mu+\alpha \Delta p_{i, t-1}+\varepsilon_{i, t}
$$

where $\Delta p_{i, t}$ is the change in the price of CDS $i$ between time $t$ and $t-1, \mu$ is a long term drift coefficient, and $\varepsilon_{i, t}$ is the error term for the return on CDS $i$ at time $t$. The equation is then tested for existing of Autoregressive Conditional Heteroscedasticity (ARCH) using the tests described in Engle (1982). As the volatility transmission among the CDS markets of developed and emerging markets is examined along with the volatility transmission within each market, a variant of multivariate GARCH model is used.

There are number of variations of MGARCH model used in the literature and two of the popular ones are VECH and BEKK models. The VECH model, which was introduced by Bollerslev et al. (1988) is expressed by:

$$
\operatorname{vech}\left(\mathrm{H}_{\mathrm{t}}\right)=\mathrm{A}_{0}+\sum_{j=1}^{q} B_{j} \operatorname{vech}\left(\mathrm{H}_{\mathrm{t}-\mathrm{j}}\right)+\sum_{j=1}^{q} A_{j} \operatorname{vech}\left(\varepsilon_{t-j}, \varepsilon_{t-j}^{\prime}\right)
$$

where $\varepsilon_{t}=H_{t}^{1 / 2} \eta_{t}, \eta_{t} \approx i i d N(0,1)$. Here, $H_{t}$ is the conditional variance-covariance matrix, and vech $\left(H_{t}\right)$ represents the vector formed by stacking the columns of a matrix, $X_{t}$.

There is a more feasible alternative model called BEKK parameterization by Engle \& Kroner (1995), which succeeds the complexity associated with $\mathrm{VECH}$ parameterization. The BEKK model makes use of quadratic forms so that no restrictions are required to guarantee a positive semi-definite $H_{t}$ matrix, a requirement for the estimated variance to be greater than or equal to zero. The BEKK parameterization for multivariate $\operatorname{GARCH}(1,1)$ model can be expressed by:

$$
H_{t+1}=C^{\prime} C+A^{\prime} \varepsilon_{t} \varepsilon_{t}^{\prime} A+B^{\prime} H_{t} B
$$


where the elements for 3 is expressed as:

$$
A=\left[\begin{array}{lll}
a_{11} & a_{12} & a_{13} \\
a_{21} & a_{22} & a_{23} \\
a_{31} & a_{32} & a_{33}
\end{array}\right] B=\left[\begin{array}{lll}
b_{11} & b_{12} & b_{13} \\
b_{21} & b_{22} & b_{23} \\
b_{31} & b_{32} & b_{33}
\end{array}\right] C=\left[\begin{array}{ccc}
c_{11} & 0 & 0 \\
c_{21} & c_{22} & 0 \\
c_{31} & c_{32} & c_{33}
\end{array}\right]
$$

Here, $A$ is a $3 \times 3$ square matrix of parameters that represents the correlation of conditional variances with past squared errors, so the elements of $A$ measure the effects of shocks or unanticipated events on conditional variances. $B$ is also a $3 \times 3$ square matrix of parameters that shows how current levels of conditional variances are affected by past conditional variances. $C$ is a 3 x 3 lower triangle matrix with six parameters.

For each equation, conditional variance, excluding constants, can be expanded for a trivariate $\operatorname{GARCH}(1,1)$ as:

$$
\begin{aligned}
h_{11, t+1}= & a_{11}^{2} \varepsilon_{1, t}^{2}+2 a_{11} a_{21} \varepsilon_{1, t} \varepsilon_{2, t}+2 a_{11} a_{31} \varepsilon_{1, t} \varepsilon_{3, t}+a_{21}^{2} \varepsilon_{2, t}^{2}+ \\
& 2 a_{21} a_{31} \varepsilon_{2, t} \varepsilon_{3, t}+a_{31}^{2} \varepsilon_{3, t}^{2}+b_{11}^{2} h_{11, t}+2 b_{11} b_{21} h_{12, t}+ \\
& 2 b_{11} b_{31} h_{13, t}+b_{21}^{2} h_{22, t}+2 b_{21} b_{31} h_{23, t}+b_{31}^{2} h_{33, t} \\
h_{22, t+1}= & a_{12}^{2} \varepsilon_{1, t}^{2}+2 a_{12} a_{22} \varepsilon_{1, t} \varepsilon_{2, t}+2 a_{12} a_{32} \varepsilon_{1, t} \varepsilon_{3, t}+a_{22}^{2} \varepsilon_{2, t}^{2}+ \\
& 2 a_{22} a_{32} \varepsilon_{2, t} \varepsilon_{3, t}+a_{32}^{2} \varepsilon_{3, t}^{2}+b_{12}^{2} h_{11, t}+2 b_{12} b_{22} h_{12, t}+ \\
& 2 b_{12} b_{32} h_{13, t}+b_{22}^{2} h_{22, t}+2 b_{22} b_{32} h_{23, t}+b_{32}^{2} h_{33, t} \\
h_{33, t+1}= & a_{13}^{2} \varepsilon_{1, t}^{2}+2 a_{13} a_{23} \varepsilon_{1, t} \varepsilon_{2, t}+2 a_{13} a_{33} \varepsilon_{1, t} \varepsilon_{3, t}+a_{23}^{2} \varepsilon_{2, t}^{2}+ \\
& 2 a_{23} a_{33} \varepsilon_{2, t} \varepsilon_{3, t}+a_{33}^{2} \varepsilon_{3, t}^{2}+b_{13}^{2} h_{11, t}+2 b_{13} b_{23} h_{12, t}+ \\
& 2 b_{13} b_{33} h_{13, t}+b_{23}^{2} h_{22, t}+2 b_{23} b_{33} h_{23, t}+b_{33}^{2} h_{33, t}
\end{aligned}
$$

The group of equations 5, 6 and 7 is a representation of how shocks and volatility are transmitted across markets and over time.

Since the parameters in equations 5, 6 ve 7 are the non-linear functions of parameters estimated in equation 3 , prior to significance tests, expected value and standard errors should be calculated for these non-linear functions. The expected value of the non-linear function (such as $2 b_{13} b_{23}$ ) will be calculated as the function of estimated parameters. The standard errors are calculated by using first order Taylor expansion and the t-statistics are provided in the related tables. $^{2}$

In sum, the aim in this model is to analyze the effect of past error terms and past conditional variances on the current conditional variance. Then the appropriate null hypothesis for testing the significance of the direct effect of past error terms (shocks or unanticipated events) on the current conditional volatility $h_{i i, t+1}$ will be:

$$
H_{0}=a_{j i}^{2}=0 \text { for } i=1, \ldots, 3 \text { and } j=1, \ldots, 3
$$

To test the significance of indirect effect of past shocks, the null hypothesis will take the following form:

\footnotetext{
${ }^{2}$ Kearney \& Patton (2000) used the same approach in their study analyzing the foreign exchange volatility interaction mechanism in European Monetary Union by MGARCH modeling. For calculation of standard errors of non-linear functions of regression parameters see also Papke \& Wooldridge (2005).
} 


$$
H_{0}=2 a_{i i} a_{j i}=0 \text { for } i=1, \ldots, 3 \text { and } j=1, \ldots, 3 \text { for } j \neq i
$$

The significance of direct effect of past conditional variances on the current conditional variance will be tested with the following null hypothesis:

$$
H_{0}=b_{j i}^{2}=0 \text { for } i=1, \ldots, 3 \text { and } j=1, \ldots, 3
$$

For the indirect effect of past conditional volatilities through the covariance terms, the null hypothesis will take the following form:

$$
H_{0}=2 b_{i i} b_{j i}=0 \text { for } i=1, \ldots, 3 \text { and } j=1, \ldots, 3 \text { for } j \neq i
$$

To estimate the tri-variate GARCH asymmetric BEKK model, the following likelihood function is constructed and maximized with a t distribution for the errors;

$$
L(\theta)=-T \ln (2 \pi)-\frac{1}{2} \sum_{t=1}^{T}\left(\ln \left|H_{t}\right|+\varepsilon_{t}^{\prime} H_{t}^{-1} \varepsilon_{t}\right)
$$

where $\theta$ represents vector of parameters to be estimated and $T$ is the number of observations. Since, the log-likelihood function is non-linear, numerical maximization techniques are used to estimate the model. As recommended by Engle \& Kroner (1995), several initial iterations using simplex algorithm are performed to obtain the initial conditions for the BHHH [Berndt, Hall, Hall, and Hausman] algorithm, which in turn provides the final estimate of the variance-covariance matrix with corresponding standard errors.

Given that the last credit crisis is considered to be worst and the most destructive one of the modern financial world, it is quite possible to expect the crisis to cause structural breaks in various financial markets. With this perspective, possible changes in the volatility transmission relationship during the crisis episode is also examined. To do this, Inclan and Tiao's iterative cumulative sums of square (ICSS) algorithm is adopted. ICSS algorithm allows for detecting multiple breakpoints in variance of a time series. Let $\varepsilon_{t}$ be a series with zero mean and unconditional variance $\sigma_{t}^{2}$.

Denote $C_{k}$, as the cumulative sum of squared observations from the first observation to the $k^{\text {th }}$ point in time:

$$
C_{k}=\sum_{t=1}^{k} \varepsilon^{2 t}, \text { where } t=1, \ldots, T \text { and } k=1, \ldots, T
$$

Define $D_{k}$ statistic as :

$$
D_{k}=\frac{C_{k}}{C_{T}}-\frac{k}{T} \text {, with } D_{0}=D_{T}=0
$$

If there is no volatility shift in the series, $D_{k}$ will look like a horizontal line when it is plotted against $\mathrm{k}$. However, if there is a sudden change in variance, we will observe $D_{k}$ statistics drifting away from zero. ${ }^{3}$

\footnotetext{
${ }^{3}$ As the financial data is known to show conditional heteroscedasticity, the assumption of constant variance within each regime has to be taken care of. This study follows Sansó et al. (2004) and uses the critical value of 1.4058 which corrects for kurtosis and explicitly accounts for conditional heteroscedasticy.
} 


\subsection{Data}

For the analysis of volatility transmission among the CDS markets, we used daily U.S. dollar denominated Turkish and Brazil sovereign CDS prices with a maturity of five years. Sovereign CDS prices and iTraxx XO index of 5-year maturity are obtained from Bloomberg. CDX index of 5-year maturity is obtained from Reuters Ecowin Pro. The sample period spans from March $22^{\text {nd }}$, 2005 to March 31 ${ }^{\text {st }}, 2011$.

The analysis is conducted in the first differences of the log of each variable. Table 1 represents the descriptive statistics of corresponding series. Volatility (as measured by standard deviation) is highest in Brazil CDS market which is followed by Turkish CDS market. The volatility pattern can be observed from the plot of daily returns of each series in Figure 2. As it is fairly common in high frequency financial data, no series are normally distributed. Along with high kurtosis and negative skewness, the Jarque-Bera test provides evidence against the hypothesis of normality in all series (the null hypothesis of Skewness $=0$ and Kurtosis = 3). The Q-statistic is used for the detection of autocorrelation and past behavior of the market is found to be significant in all series at $10 \%$ significance level.

Tabela 1: Descriptive statistics for return series

\begin{tabular}{lcccc}
\hline & TR & BR & CDX & iTraxx XO \\
\hline Mean & 0,00004 & $-0,00106$ & 0,00140 & 0,00008 \\
Std. Dev. & 0,033 & 0,040 & 0,034 & 0,004 \\
Skewness & 0,795 & 0,673 & $-0,226$ & 0,334 \\
Kurtosis & 7,392805 & 9,945753 & 10,03755 & 7,728540 \\
Jarque-Bera & 786,49 & 1803,98 & 1792,37 & 821,93 \\
$\quad$ Probability & 0,000000 & 0,000000 & 0,000000 & 0,000000 \\
Q(11) & & & & \\
$\quad$ Probability & & & & \\
\hline
\end{tabular}

Table 1.A. Pre-break statistics

\begin{tabular}{lcccc}
\hline & TR & BR & CDX & iTraxx XO \\
\hline Mean & $-0,00089$ & $-0,00052$ & $-0,00076$ & 0,00027 \\
Std. Dev. & 0,042 & 0,050 & 0,035 & 0,007 \\
Skewness & 0,096 & $-0,012$ & 0,343 & 0,071 \\
Kurtosis & 8,317316 & 15,54038 & 11,90782 & 5,960596 \\
Jarque-Bera & 746,70 & 4147,78 & 2105,27 & 231,71 \\
$\quad$ Probability & 0,000000 & 0,000000 & 0,000000 & 0,000000 \\
Q(11) & & & & \\
\multicolumn{1}{c}{ Probability } & & & & \\
\hline
\end{tabular}

Table 1.B. Post-break statistics

\section{Empirical Results}

Two tri-variate models with four different indicators are the focus of this study. The first model combines (estimates) two emerging markets' sovereign CDS 

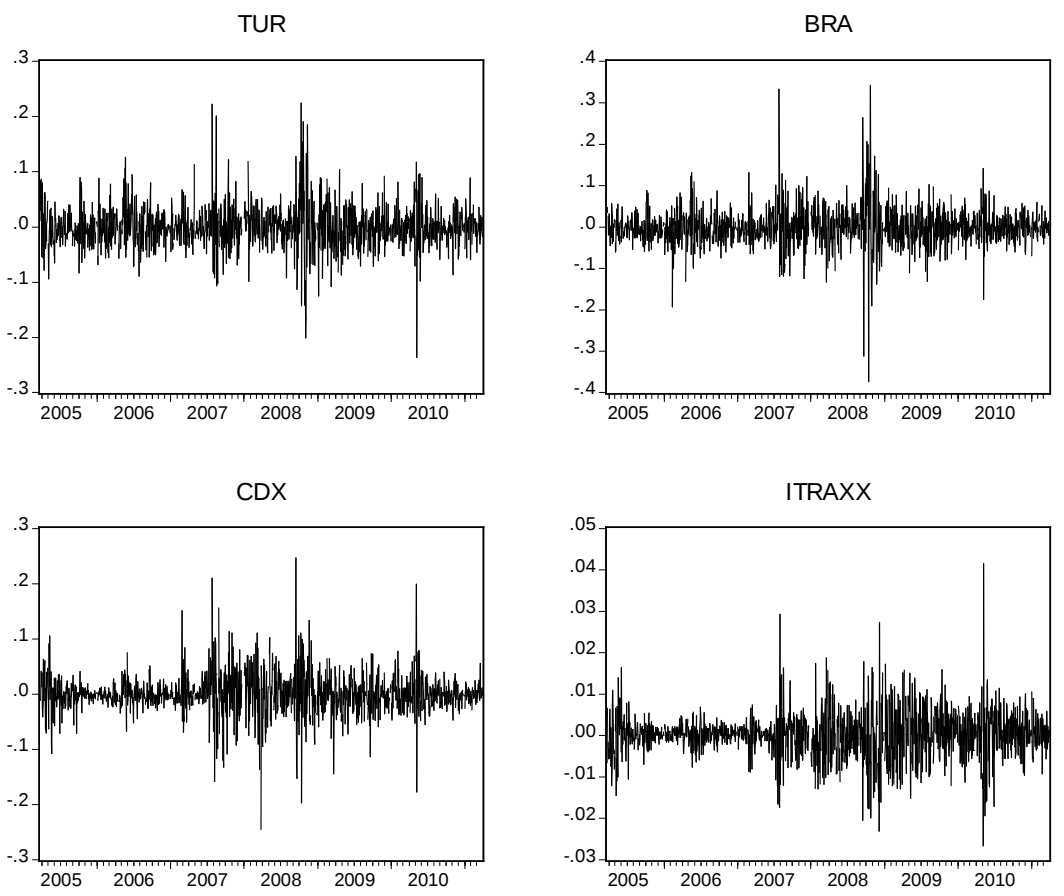

Figura 2: Daily Returns of Turkish CDS, Brazilian CDS, iTraxx XO and CDX indexes

spreads (Turkey and Brazil) with a developed CDS market which is represented by CDX index. In the second model, iTraxx XO index is used as another developed CDS market index.

\subsection{Structural Break}

Using the described ICSS algorithm, the first turning point is detected on September $12^{\text {th }}, 2008$. The identified break point matches with the collapse of Lehman Brothers (September 15 $5^{\text {th }}, 2008$ ) and higher risk expectations among all of financial markets. The sudden increase in the CDX index of Emerging Markets in September 2008 (see Figure 1) supports our detected break point as well. The algorithm detected no further break points and the analysis is conducted by two sub-periods: pre-break period (from March 22 ${ }^{\text {nd }}, 2005$ to September $12^{\text {th }}, 2008$ and post-break period (September 15 $5^{\text {th }}, 2008$ to March $\left.31^{\text {st }}, 2011\right){ }^{4}$

The estimation results of multivariate GARCH model with BEKK parameterization for each variance equation are reported in Table 2 and Table 3 . The symbol $h_{11, t}$ represents the conditional variance for Turkish CDS market at time $t$, and $h_{12, t}$ represents the conditional variance between the CDS returns of Turkey and Brazil. As explained earlier, the third parameter in two models

\footnotetext{
${ }^{4}$ Rather than using a dummy variable controlling the detected break point, sub-period analysis is conducted to be able to analyze the possible change in the dynamics of interaction mechanism among the markets. A dummy variable wouldn't allow us to compare the before - and after — break period volatility dynamics.
} 
are different. In the first model, the third parameter represents US market $(C D X)$ and in the second model, it represents European market (iTraxxXO). The error term $\varepsilon$ represents the shocks or news on each parameter, i.e. $\varepsilon_{1, t}^{2}$ represents the deviation from the mean caused by an unexpected event in Turkish CDS market at time $t$. The cross values i.e. $\varepsilon_{1, t} \varepsilon_{2, t}$ represent the news or shocks in Turkish and Brazilian markets.

While examining the results of both models, only the significant terms at $5 \%$ level are discussed. Table 2 reports the estimation results for Turkish and Brazilian CDS market together with CDX index for both pre-break and post-break periods. Before the crisis, it's observed that Turkish CDS market is only directly affected by its own shocks and its past volatility. Although the Brazilian market shocks and past volatility affect the Turkish CDS market volatility indirectly during the pre-crisis period, it seems that the indirect effect of Brazilian market shocks disappear after the crisis.

Shock transmission mechanism between the Turkish and Brazilian CDS markets presents a common pattern that the Brazilian CDS market is affected indirectly by the news from the Turkish market as well as by its own news before the crisis. In terms of the effect of past volatility, it's directly and indirectly affected by its own past volatility and also the volatility generated from Turkish CDS and U.S. CDS markets. However, after the detected break in financial markets, most of the linkages among the Brazilian and other CDS markets seems to be broken. The only direct effect on Brazilian CDS market volatility is its own past volatility. For the CDX index volatility, it's observed that U.S. CDS market is affected by its own news and past volatility, and it's indirectly affected by the news from both Brazilian and Turkish CDS markets through the covariance terms. The volatility from Brazilian CDS market indirectly affects the CDX index volatility in the next period. CDX index volatility shows a similar pattern with that of Brazilian market such that the direct and indirect effects of market shocks disappear after the break point. Based on the first model results, it can be generalized that the shock and volatility transmission is marked among the CDS markets before the financial markets shift into a new phase. However, after the shift, each CDS market volatility seems to draw a more isolated pattern than the others.

When it comes to interpret the results for Turkish, Brazilian and European CDS markets, Table 3 should be taken into account. In this setup, Turkish CDS market again presents a more isolated pattern with only direct effect of its own shocks and past volatility. After the break point, tough, while the direct effect of its own shocks disappears, the indirect effect of Brazilian CDS market volatility enters into the transmission mechanism. For the Brazilian CDS market volatility, its own shocks and past volatility seems to have a direct effect while the shocks from iTraxx XO have an indirect effect. One interesting result detected for Brazilian CDS market is that there is no change in volatility transmission mechanism after the break point. Contrary to the Brazilian CDS market, iTraxx XO index volatility presents diverse patterns before and after the break. It seems to be affected directly and indirectly from Brazilian CDS market shocks and past volatility as well as its own shocks and own past volatility during the pre-break period. However, after the break, it is observed that all the direct linkages with Brazilian CDS market is broken and there is direct and indirect effect of Turkish CDS market volatility.

In terms of the spillover of shocks from one market to other market's variance, Brazilian and Turkish sovereign CDS markets seem to be more inte- 
grated with European iTraxx XO index. This is mostly attributable to model parameters being in the same investment grade during the time of the analysis. The volatility transmission is more pronounced again in the second setup where the European companies' CDS spreads are considered. The iTraxx XO index is generally considered as a leading indicator among the CDS markets by the investors and market professionals. However, the absence of a direct effect of the index volatility on Turkish CDS market but the significant volatility interaction among the emerging countries'CDS markets calls for a reconsideration of iTraxx $\mathrm{XO}$ index as a leading indicator. In terms of the volatility pattern before and after the break, CDX index volatility seems to break apart. As the financial crisis of 2007 is considered to be the crisis of developed financial markets and ignited from the U.S. based financial institutions, it is quite possible to observe for the CDX index an isolation from the other CDS markets. In more general terms, CDS market volatility presents a bit more isolated pattern during the crisis period, which implies that the risk perceptions for each market is determined more with its own fundamentals rather than those of other markets.

\section{Conclusion}

A number of studies have investigated the volatility transmission mechanism among the financial markets. In this study, we draw the attention to a relatively new financial instrument, Credit Default Swaps and explore the volatility spillover among the related emerging and developed markets. We further aim to address whether there is any change in volatility transmission dynamics during the recent financial distress. Structural break analysis indicate that there is a break in the volatility behavior of interested CDS markets around the time of Lehman Brothers' collapse and we divide our data into two sub-samples representing before and after 2008 credit crunch. Multivariate GARCH modeling is employed using daily returns data. The results show that there is a significant interaction among the CDS markets under investigation. Turkish CDS market volatility responds both to it's own and Brazilian CDS market's unanticipated events and past volatility in pre-crisis period while the impact of Brazilian market shocks disappears in crisis period. The volatility of two CDS indexes, CDX and iTraxx XO, illustrating developed markets do not follow a different transmission mechanism than the emerging markets' volatility, reacting both to market shocks and past volatility. While both iTraxx and CDX markets are affected by their own shocks and volatility before the crisis, iTraxx $\mathrm{XO}$ is indirectly affected by Brazilian CDS market shocks and volatility at the same period but the links are broken after crisis period. After crises there is still direct and indirect affect of Turkish CDS market on iTraxx CDS market. Again for the CDX market, volatility links are observed to be loosened and CDX market volatility is only indirectly affected by Brazilian CDS market volatility. The question raised in this study was whether the volatility is transmitted among the developed and emerging markets in both directions. Although there is a pattern change in the crisis period, according to our results, volatility spillover occurs in both directions and there is no sign of the dominance of developed markets in volatility transmission mechanism. In the post-crisis period, CDX market seems to disintegrate from the other CDS markets. Overall, understanding the transmission of shocks and volatility among 


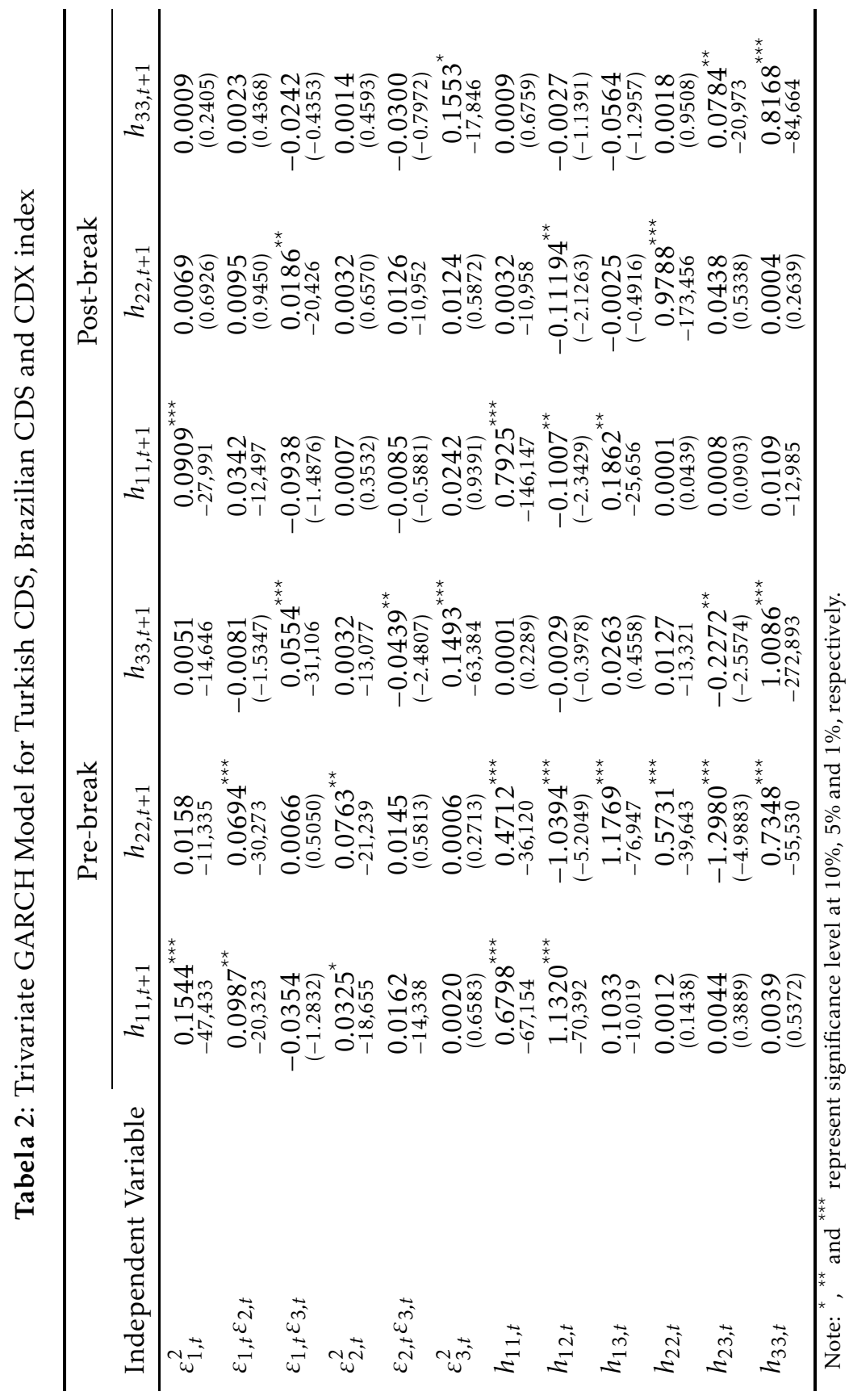




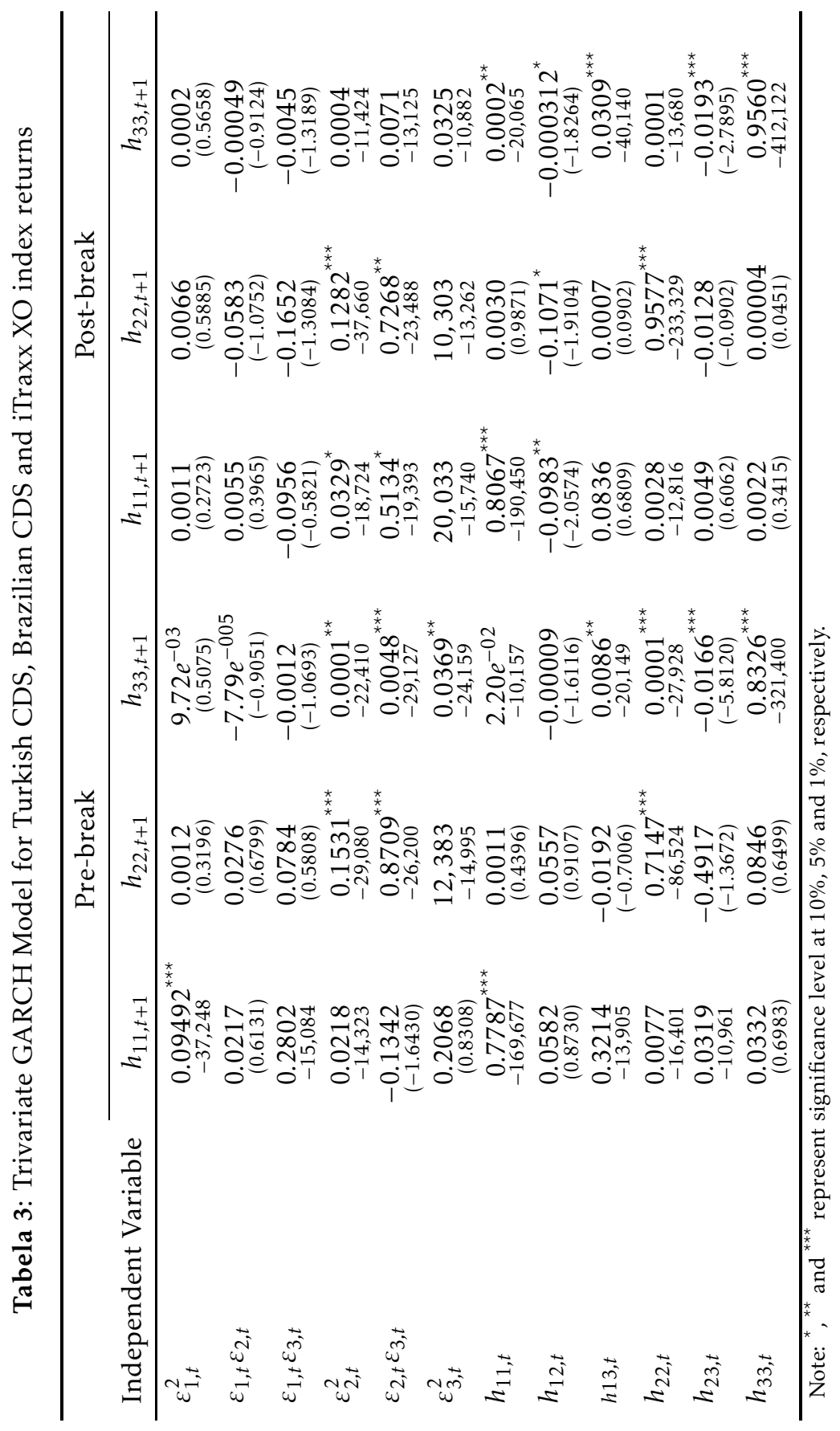


the CDS markets delivers valuable information for financial market participants and may be useful for optimal portfolio allocation decisions. Investors should examine not only the CDS market that they have in their portfolio but also the others since a shock affecting one market will eventually affect the others through the transmission mechanism shown in this study. Further research will be on developing an optimal hedging strategy based on the results gained from this study.

\section{Referências Bibliográficas}

Arshanapalli, B. \& Doukas, J. (1993), 'International stock market linkages: Evidence from the pre- and post-october 1987 period', Journal of Banking and Finance 17, 193-208.

Blanco, R., Brennan, S. \& Marsh, I. W. (2005), 'An empirical analysis of the dynamic relation between investment-grade bonds and credit default swaps', Journal of Finance 60, 2255-2281.

Bollerslev, T. P., Engle, R. F. \& Wooldridge, J. M. (1988), 'A capital asset pricing model with time varying covariance', Journal of Political Economy 96, 116-131.

Chan-Lau, J. A. \& Kim, Y. S. (2004), Equity prices, credit default swaps, and bond spreads in emerging markets, Working Paper WP/04/27, IMF.

Chukwuogor, C. (2007), 'Stock markets returns and volatilities: A global comparison', Global Journal of Finance and Banking Issues 1(1), 1-27.

Dailami, M., Padou, J. J. \& Masson, P. (2005), Global monetary conditions versus country-specific factors in the determination of emerging market debt spreads, Policy Research Working Paper Series 3626, The World Bank.

Engle, R. F. (1982), 'Autoregressive conditional heteroscedasticity with estimates of the variance of the u.k. inflation', Econometrica 50, 987-1008.

Engle, R. F. (1993), 'Common volatility in international equity markets', Journal of Business and Economic Statistics 11, 167-176.

Engle, R. F. \& Kroner, K. F. (1995), 'Multivariate simultaneous generalized arch', Econometric Reviews 11, 122-150.

Ewing, B. T., Malik, F. \& Ozfidan, O. (2002), 'Volatility transmission in the oil and natural gas markets', Energy Economics 24, 525-538.

Frank, N. \& Hesse, H. (2009), Financial spillovers to emerging markets during the global financial crisis, Working Paper 8634, NBER.

Frankel, J. A. \& Roubini, N. (2001), The role of industrial country policies in emerging market crises, Working Paper 09/104, IMF.

Hamao, Y. \& Masulis, R. W. Ng, V. (1990), 'Correlations in price changes and volatility across international stock markets', The Review of Financial Studies 3, 281-307. 
Hassan, S. A. \& Malik, F. (2007), 'Multivariate garch modeling of sector volatility transmission', The Quarterly Review of Economics and Finance 47, 470480 .

Hull, J. C. (2008), Options, Futures and Other Derivatives, 6th edition edn, NJ: Prentice Hall.

Karolyi, G. A. (1995), 'A multivariate garch model of international transmission of stock returns and volatility', Journal of Business and Economic Statistics 13, 11-25.

Kearney, C. \& Patton, A. J. (2000), 'Multivariate garch modeling of exchange rate volatility transmission in the european monetary system', Financial Review 41, 29-48.

King, M. A. \& Wadhwani, S. (1990), 'Transmission of volatility between stock markets', The Review of Financial Studies 3, 5-33.

Lin, W. L., Engle, R. F. \& Ito, T. (1994), 'Do bulls and bears move across borders? international transmission of stock returns and volatility', The Review of Financial Studies 7, 507-538.

Meng, L., Gwilym, O. \& Varas, J. (2009), 'Volatility transmission among the cds, equity, and bond markets', The Journal of Fixed Income 18(3), 33-46.

Milunovich, G. \& Thorp, S. (2006), 'Valuing volatility spillovers', Global Finance Journal 17(1), 1-22.

Papke, L. E. \& Wooldridge, J. M. (2005), 'A computational trick for deltamethod standard errors', Economics Letters 86, 413-417.

Sansó, A., Aragó, V. \& Carrion-i Silvestre, J. L. (2004), 'Testing for changes in the unconditional variance of financial time series', Revista de Economía Financiera 4, 32-53.

Savva, C. S. (2009), 'International stock markets interactions and conditional correlations', International Financial Markets, Institutions, and Money 19(4), 645-661.

Tanizaki, H. \& Hamori, S. (2008), 'Volatility transmission between japan, u.k. and u.s. in daily stock returns', Empirical Economics .

URL: http://dx.doi.org/10.1007/s00181-007-0182-x

Weigel, D. D. \& Gemmill, G. (2006), 'What drives credit risk in emerging markets? the roles of country fundamentals and market co-movements', Journal of International Money and Finance 25, 476-502.

Xu, X. E. \& Fung, H. G. (2005), 'Cross-market linkages between u.s. and japanese precious metals futures trading', Journal of International Financial Markets, Institutions and Money 15, 107-124. 